\title{
LÍNGUA PORTUGUESA NO MARANHÃO: UM PERCURSO HISTORIOGRÁFICO DO SÉCULO XIX
}

\author{
Sonia Maria Nogueira ${ }^{1}$ \\ Neusa Maria O. Barbosa Bastos ${ }^{2}$
}

\begin{abstract}
Resumo: O presente trabalho enfoca o processo de implementação do ensino de Língua Portuguesa no Maranhão, do século XIX, tendo como objetivo descrever como se adquiriu e desenvolveu o conhecimento lingüístico da Língua Portuguesa nesse período. Para tanto, fixa sua base teórica na Historiografia Lingüística para enfocar as implicações culturais dos diversos momentos de tal processo. Assim sendo, os procedimentos metodológicos privilegiarão os três princípios traçados por Koerner (1996) a fim de desvelar, por meio das fontes primárias e secundárias, o clima de opinião vigente em cada século especificado e o percurso historiográfico da Língua Portuguesa no Maranhão.
\end{abstract}

Palavras-chave: Língua Portuguesa, Historiografia Lingüística, Questão Maranhense.

\section{Perspectivas iniciais}

O presente trabalho foi amadurecido durante as discussões promovidas no Seminário A Língua Portuguesa no século XX: uma perspectiva historiográfica, no Programa de Estudos Pós-Graduados em Língua Portuguesa da PUC-SP. Tal situação nos incentivou à investigação historiográfica do ensino da Língua Portuguesa no Maranhão. Assim sendo, nossa proposta trata de maneira mais ampla da questão: Como se deu o processo de implementação do ensino da Língua Portuguesa no Maranhão do século XIX, e também como se deu o processo da implantação de uma política lingüística? Neste texto, especificamente, tratar-se-á do século XIX.

Em virtude disso, a reflexão sobre os movimentos da Língua Portuguesa se faz necessária nos meios acadêmicos. Desta maneira, o processo histórico abrange a formulação do conhecimento lingüístico através dos seus mecanismos de produção e recepção e, portanto, questionar o percurso historiográfico lingüístico do Maranhão nos direciona a definir o problema desta pesquisa.

Inclusive, o fomento à pesquisa tem sido imprescindível a discussões quanto às questões da identidade cultural e lingüística do povo brasileiro e muitas investigações têm sido empreendidas.

\footnotetext{
${ }^{1}$ Universidade Estadual do Maranhão (UEMA) / Instituto de Pesquisas Lingüísticas "Sedes Sapientiae" para estudos de português (IP-PUC/SP). Rua Godofredo Viana, s/n, centro, 65900000, Imperatriz/MA.

${ }^{2}$ Programa de Estudos Pós-Graduados em Língua Portuguesa - Pontifícia Universidade Católica de São Paulo / Instituto de Pesquisas Lingüísticas "Sedes Sapientiae" para estudos de português (IP-PUC/SP). Rua Ministro de Godoy, 969, Perdizes, 05015901, São Paulo/SP.
} 
No entanto, podemos perceber a carência de estudos específicos do ensino de Língua Portuguesa no Maranhão. A falta de material referente à historiografia lingüística e a política linguística no Maranhão, até a primeira metade do século XX, constitui uma lacuna significativa na área das Ciências Humanas.

Sendo assim, impõe-se a necessidade de trabalhos que venham a abranger a publicação didática, antologia de textos, leis, decretos de ensino de Língua Portuguesa, tomadas de atitudes, jornais, críticas. Tais trabalhos, por sua vez, virão a apresentar interpretações do passado de forma mais transparente para os leitores menos experientes da atualidade.

Partindo do pressuposto de que não encontramos material teórico, em circulação hoje, que discuta o ensino da Língua Portuguesa no Maranhão, pretendemos pesquisar sobre o processo de implementação desse ensino do século XIX, e também como se deu o processo da implantação de uma política lingüística para a região, a qual passou por grandes oscilações políticas desde a chegada dos colonizadores.

Nosso objetivo geral consiste em descrever e explicar como se adquiriu, produziu e desenvolveu o conhecimento lingüístico da Língua Portuguesa no Maranhão, de forma a contribuir para os estudos historiográficos da Língua Portuguesa no Brasil.

Especificamente, buscaremos verificar o que efetivamente contribuiu para o processo de implementação desse ensino, e caracterizar o estudo no recorte da história por meio dos aspectos filosóficos, sociais, políticos, econômicos e culturais. Além do que identificaremos quais as fontes primárias, as fontes secundárias, as diversas publicações que traçam o percurso historiográfico da Língua Portuguesa no Maranhão. Salientamos, ainda, que pretendemos analisar como podemos estabelecer um entendimento tanto histórico quanto crítico do texto lingüístico pesquisado e, verificar, de acordo com as categorias selecionadas, qual método foi adotado nesse processo de implementação.

Para tanto, os procedimentos metodológicos adotados serão constituídos a partir da ampliação da bibliografia historiográfica lingüística, que representa um aprofundamento dos conhecimentos acerca do ensino de Língua Portuguesa no Brasil. Com efeito, contribuirá à ampliação dos conhecimentos referentes ao processo de implementação do ensino de Língua Portuguesa no Maranhão, assim como possibilitará o levantamento dos documentos que traçam o percurso historiográfico da Língua Portuguesa, nos arquivos maranhenses, para posterior análise.

\section{Percurso Historiográfico}

Este trabalho insere-se na Linha de Pesquisa Histórica e descrição da Língua Portuguesa, mais especificamente centrado nas investigações levadas a efeito no Grupo de Pesquisa de Historiografia de Língua Portuguesa do IP-PUC/SP.

A concepção de Historiografia Lingüística encontra-se vinculada tanto à concepção de Historiografia, tanto quanto de História, uma vez que ultrapassa o papel fundamental do registro dos acontecimentos históricos, bem como a narrativa desses acontecimentos. Pois, a Historiografia Linguística constitui-se num 'modo de escrever a história do estudo da linguagem baseado em princípios científicos', afirma Koener $(1996,: 45)$. 
Assim sendo, torna-se relevante abordar algumas definições de História Intelectual, pertinentes à Rodrigues da Silva (apud LOPES, 2002:15). A primeira foi elaborada por Carl Schorske, o qual afirma que "o historiador procura localizar e interpretar temporalmente o artefato num campo que se intersectam duas linhas". Sendo que uma delas é "vertical, ou diacrônica", e a outra é "horizontal, ou sincrônica", pois por meio desta "determina a relação do conteúdo do objeto intelectual com o que vai surgindo ao mesmo tempo noutros ramos ou aspectos de uma cultura". A segunda, por sua vez, elaborada por Robert Darnton, assegura que a História Intelectual vem a ser "o estudo dos pensamentos informais, (das correntes de opinião e das tendências literárias)."

Deste modo, o objeto da História Intelectual, de acordo com Rodrigues da Silva (apud LOPES, op.cit.:16), possibilita dois pólos de análise, "o conjunto de funcionamento de uma sociedade intelectual", assim como "as características de um momento histórico e conjuntural que impõe formas de percepção e de apreciação". Por isso, a História Intelectual "teria por principal pressuposto restituir, do ponto de vista sociológico, filosófico e histórico, o contexto de produção de uma obra”.

Convém ser ressaltado, ainda, que o termo 'programa de investigação', formulado por Swiggers $\left(1981,1991^{a}{ }^{\mathrm{a}}\right.$, 1992 $\left.^{\mathrm{a}}\right)$, foi utilizado por Altman (1998:37-8) em detrimento do termo paradigma para tratar das dimensões ditas internas e externas do desenvolvimento de uma disciplina científica, com a finalidade de repropô-las. Quanto à dimensão interna dos paradigmas, apresentam-se os quatro tipos principais de programas recorrentes, do ponto de vista da dinâmica interna dos problemas enfocados na história da linguística, considerados por Swiggers: O programa de correspondência na história das idéias e das práticas de análise lingüística com o objetivo de examinar as correspondências entre linguagem, pensamento e realidade.

O outro seria o programa descritivista, que concebe a língua como um conjunto de dados formais, autônomos, ordenáveis de maneira sistemática. O terceiro programa é o sócio-cultural, no qual a língua é estudada como um fato social e cultural com o objetivo de uma "análise da variação das formas lingüísticas no âmbito de uma comunidade lingüística e no âmbito das performances lingüísticas dos falantes”. E, finalmente, o programa de projeção visa "à projeção de um sistema formalizado - uma linguagem categorial construída pelo lingüista-lógico - em certos fragmentos de uma determinada língua”.

A Historiografia, com efeito, nasceu na França, instituída como método interdisciplinar e, com isso, tem demonstrado a intenção de registrar os feitos humanos em sua totalidade. No Brasil, as valiosas contribuições são advindas dos estudiosos que buscam resgatar os fatos relevantes do passado lingüístico, além de seu processo de produção e recepção. Podemos elencar a Prof ${ }^{a} \operatorname{Dr}^{a}$ Neusa Maria Oliveira Barbosa Bastos, do Grupo de Pesquisa de Historiografia da Língua Portuguesa (GPeHLP - IPPUC/SP); o Prof. Dr. José Marcelo Luna de Freitas, da UNIVALI; a Prof ${ }^{a}$ Dr $^{a}$ Maria Cristina Salles Altman, da USP; a Prof ${ }^{\mathrm{a}}$ Dr $^{\mathrm{a}}$ Nancy dos Santos Casagrande, (GPeHLP IP-PUC/SP).

Assim sendo, Bastos et al. (2002) enfatiza que "Historiografia não pode ser vista como uma simples 'crônica', ou seja, listas de datas, nomes, títulos e eventos ligados às línguas e à linguagem. A atividade historiográfica requer seleção, ordenação, reconstrução e interpretação dos fatos relevantes".

Convém ser ressaltado que considerar um modelo único de cidadão e de sociedade pauta-se em princípios capitalistas homogeneizantes, o qual generaliza as diversas instituições sociais, deixando de caracterizá-las em sua complexidade e na sua dimensão. Uma metodologia de ensino de Língua Portuguesa para os nativos 
brasileiros, um dos objetos de reflexão desta pesquisa, paralelamente ao processo educativo e as ações que se desenvolvem para elaborar e produzir conhecimentos, pode ser concebida como área, até então, pouco explorada.

Em vista disso, nossa prática investigativa está voltada à verificação e compreensão do processo de implementação do Ensino de Língua Portuguesa no Maranhão do século XVIII ao XX. Trata-se de uma pesquisa que envolve uma instituição pública de ensino, os educadores e os alunos que exercitam um trabalho pedagógico e que, até então, não estão dispensando devida atenção ou, mesmo, interesse à política linguiística do ensino da Língua Portuguesa no Maranhão.

Tomaremos como corpus de análise fontes documentais primárias, entre elas gramáticas de maranhenses, jornais, decretos de ensino de Língua Portuguesa, publicados no período em questão,

O que temos observado há algum tempo, em nossos estudos, são acentuadas críticas, sobretudo a algumas metodologias do ensino de língua. Porém, pouco se tem produzido para amenizar tal situação, por conseguinte existe a necessidade de reavaliar, ou até mesmo de problematizar, alguns (pré)conceitos que os educadores têm a respeito do ensino da língua, e que exigem exercícios diários de reflexão e de prática pedagógica.

Isso possibilita trazer à sala de aula novos conhecimentos para que unidas, escola e investigação historiográfica, possam efetivar um trabalho de informação e produção de saberes, junto ao aluno, sem tomar posições a priori extremadas, como apocalípticas ou como integradas. A investigação historiográfica está, inclusive, contribuindo com a escola, ela pode também atuar como um dos elementos pedagógicos para contribuir para a construção de conhecimentos e formar cidadãos.

Sendo assim, há uma expectativa de que este trabalho possa ser útil aos professores, como também para os demais profissionais da educação que atuam no ensino médio e universitário, e à própria pesquisadora. A importância desta pesquisa se consolida à medida que os problemas relacionados à elaboração, ao desenvolvimento e à discussão do tema em si surgirem no decorrer da pesquisa.

Da mesma forma, torna-se útil aos leitores e aos professores que questionam uma postura teórica baseada num processo que foi reproduzido no Ensino de Língua Portuguesa no Maranhão, provavelmente, com características doutrinárias e de dominação apresentadas nas gramáticas de Fernão de Oliveira e de João de Barros. Uma vez que tais obras foram escolhidas e aplicadas, didaticamente falando, também em Portugal. É relevante, pois, a análise das fontes documentais primárias, tais como gramáticas de autores maranhenses, a fim de que, numa análise comparativa, seja feita uma releitura da postura da política lingüística do Maranhão.

Nesse aspecto, tencionamos contribuir com base e material orientador no encaminhamento de prováveis tomadas de decisões quanto à prática pedagógica. Desse modo, levar os docentes a se desassossegarem do lugar fixista em que se encontram e, se possível, a alcançarem algum êxito, ou satisfação, no processo de elaboração e formação de conhecimento no contexto educacional.

Convém enfatizar, ainda, que a questão da identidade cultural e lingüística do povo brasileiro tem sido alvo de reflexões de muitos pesquisadores nos últimos anos. $\mathrm{Na}$ pluralidade de raça, de cores e de línguas, permaneceram traços da cultura do colonizador.

Do processo de colonização, então, fizeram parte a fé e a educação, tendo sido instaurados os primeiros colégios, no Brasil, pelos jesuítas para a conversão: primeiro, na língua tupi, depois, na Língua Portuguesa. 
Sendo assim, torna-se imprescindível a compreensão de Historiografia e Historiografia Linguística (HL) para que possamos nortear nossa investigação científica. Pois, a primeira, em sentido amplo, compreende-se como forma de registro dos feitos históricos. A Historiografia passou por um processo de adaptação aos paradigmas que nortearam os estudos históricos.

Pois, se a História resumia-se à narrativa dos acontecimentos, a Historiografia tinha como papel fundamental o registro desses acontecimentos sem problematizá-los ou questioná-los. Era a vigência do paradigma da ciência normal que "[...] não tem como objetivo trazer à tona novas espécies de fenômeno: na verdade aqueles que não se ajustam aos limites do paradigma freqüentemente nem são vistos [...]", de acordo com Kuhn (2000:45).

Por outro lado, é preciso considerar que tais fenômenos, aos quais se refere Kuhn, acabam por suscitar novas rupturas no paradigma vigente, pois se, num primeiro momento, eles não são considerados, num segundo instante, passam a ser os responsáveis pelo nascimento de novas visões na ciência. Nesse caso, é importante levarmos em conta as várias rupturas pelas quais a História, na qualidade de ciência, já passou. Os estudos de HL perpassam os de Historiografia e, por isso, torna-se relevante abordar, de forma concisa, esta última.

Em virtude disso, ressalta-se que, no campo historiográfico, a maior contribuição, na busca de um novo método, é dada por Lucien Febvre e Marc Bloch, no início do século XX, na França com a fundação da revista Annales, no intuito maior de promover um novo tipo de História e, certamente, de Historiografia.

Houve, com efeito, uma renovação dos estudos historiográficos a qual ultrapassa o período da escola dos Annales, de 1929 a 1989. A revista dos Annales, por sua vez, propunha aos historiadores mudança nos seus modos de trabalhar e em seus métodos, no entanto não determinava uma nova filosofia da história ou um novo dogma, mas apresentava-lhes novos horizontes, de acordo com o historiador Geoffrey Barraclough (apud CARDOSO \& VAINFAS, 1997:07).

Relevante se faz, ainda, constar uma síntese elaborada por Cardoso .\& Vainfas (op.cit.:07-08) sobre a historiografia francesa, tendo como núcleo e ponto de encontro a revista dos Annales, que contempla suas duas primeiras gerações, no período de 1929 até 1969. Um ponto básico abordado trata da substituição de uma "história-narração" por uma "história-problema", de acordo com a formulação de hipóteses de trabalho, além da história apropriar-se de conceitos e problemáticas, métodos e técnicas, inclusive da quantificação sistemática e uso de modelos das ciências sociais em favor de estudos históricos, em virtude de ser menos estruturada em relação a tais ciências.

Outro ponto abordado consta da necessidade de explicar os vínculos entre técnicas e economia, poder e mentalidades, para a formulação de uma síntese global do social, incluindo as diferenças de ritmo e fase entre os diversos níveis do social. E, assim, surgem as temáticas econômicas, demográficas e relativas às mentalidades coletivas, além da valorização da história oral, em detrimento da história centrada em fatos isolados e das fontes escritas.

Há, ainda, a abordagem da questão da pluralidade dos níveis da temporalidade, tratada como uma tomada de consciência importante, uma vez consistir na curta duração dos acontecimentos, no tempo médio das conjunturas e na longa duração das estruturas. Salienta ainda a preocupação com o espaço através da história, iniciados os estudos por meio da tradicional ligação com a geografia humana.

E, por último, o ponto básico que trata da história vista ao mesmo tempo como "ciência do passado" e "ciência do presente", tendo em vista que "o conhecimento do presente é condição sine qua non da cognoscibilidade de outros períodos históricos" e, 
também, que a história-problema permite não só ao historiador, mas também aos seus contemporâneos a que se dirige, uma compreensão melhor das lutas de hoje.

A terceira geração dos Annales, intitulada Nova História ou História das Mentalidades, sofre considerável mudança de rumos, defendendo a abordagem quantitativa ou serial, seu posterior abandono em favor da micro-história e da antropologia. Os estudos, portanto, dos historiadores franceses "seguiam em paralelo a movimentos existentes nos Estados Unidos e em outras partes do mundo", porém nem sempre com o sucesso dos primeiros, assevera Burke (1997:122).

Sendo assim, Cardoso (op.cit.:441) identificou o paradigma iluminista, no período de 1950 a 1968, a favor de uma história científica e racional, que admite a "existência de uma realidade social global a ser historicamente explicada", e destacou o marxismo e as duas primeiras gerações dos Annales suas manifestações mais expressivas. Além desse, o paradigma pós-moderno, no período de 1968 a 1989, que "tendia a enfatizar as representações construídas historicamente", e seu suporte teórico e filosófico assentaria em semi-racionalistas, irracionalistas, e outros.

Por outro lado, Ronaldo Vainfas (1997:448-9) assegura que há divergências entre um enfoque hipotético-dedutivo, generalizante e macroexplicativo, e uma abordagem indiciária, no entanto a história deve estar autorizada a combinar abordagens distintas.

Após tais considerações gerais sobre Historiografia, abordaremos estudos acerca da HL. A atividade historiográfica em Lingüística não se resume "a uma simples compilação de datas, fatos, títulos e nomes relacionados com os estudos das línguas e da linguagem" e, por isso, difere da história, uma vez que apresentam estatutos e dimensões diferentes, de acordo com Altman (op.cit.:23, 34-36). Nesta perspectiva científica, a Historiografia institui-se como método interdisciplinar, pelo fato de considerar a colaboração de outras disciplinas, quais sejam: a Sociologia, a Psicologia, a Economia, a Geografia e também a Lingüística, revelando-se, assim, a intenção de registrar os feitos humanos em sua totalidade.

Visto que nosso interesse está centrado em compreender a HL, identificaremos as acepções do termo em sua totalidade. Para isso, tomamos como base as palavras de Koerner (op.cit.:45) quando diz da necessidade de compreendermos a HL como "modo de escrever a história do estudo da linguagem baseado em princípios científicos" e, assim sendo, não mais como mero registro da historia da pesquisa lingüística. Sabemos que essa nova concepção requer um olhar mais cuidadoso por parte do historiógrafo, que se diferenciará do olhar do historiador a partir do momento em que a HL se estabelece como disciplina.

Para que isso de fato aconteça, é preciso recuperar o passado lingüístico que se apresenta como parte integral da disciplina, inclusive no que diz respeito à Linguíística como ciência, não descartando sua influência em outras ciências como a Psicologia, a Sociologia e a Ciência Política. Tal natureza interdisciplinar requer do investigador um conhecimento amplo dos diversos campos científicos, pois seu campo de investigação deveria comportar vieses que consistiriam em:

[...] favorecer o restabelecimento dos fatos mais importantes do nosso passado lingüístico 'sine ira et studio'e explicar, tanto quanto possível, as razoes da mudança de orientação e de ênfase e a possível descontinuidade que delas se pode observar, sua prática requer, ainda, capacidade de síntese, isto é, a faculdade de destilar o essencial da massa dos fatos empíricos coligidos a partir de fontes primárias. (KOENER, op. cit.:47) 
Nesse sentido, tem início a discussão sobre a tarefa do historiador e a do historiógrafo, sendo delegadas a cada um obrigações que interferem na instauração da HL como disciplina. Diante disso, convém ressaltar os três princípios traçados por Koener (op. cit.): o princípio de contextualização que traça o clima de opinião, uma vez que aborda as correntes intelectuais do recorte em estudo, além da situação sócioeconômica, política e cultural. O princípio de imanência tenta estabelecer um entendimento global tanto histórico quanto crítico, caso seja possível filológico, do texto lingüístico em análise. Após esses, o princípio de adequação que insere aproximações modernas do vocabulário técnico, que permitem a apreciação de um determinado trabalho.

Saliente-se, por conseguinte, que o historiógrafo, na busca de caminhos próprios, requer também motivações, estas foram elencadas por De Clerq \& Swiggers (1991) e que, ao longo da história da HL, seriam fundamentadas em 5 tipos. A saber, motivação de fazer a HL: 1. como sujeito enciclopédico, como "ramos"de uma enciclopédia do saber; 2. como ilustração do progresso de conhecimento; 3 . com o objetivo de defender, difundir ou promover um modelo lingüístico particular em detrimento de outros; 4. como descrição e explicação de conteúdos de doutrina, inserida em um contexto histórico e cientifico e, também, 5. como testemunha exterior sobre uma realidade social, "colorida"pelas concepções e práticas lingüísticas.

Assim sendo, devemos transcender as histórias da lingüística, o que nos possibilita escrever uma história da lingüística baseada nas reflexões e nas situações linguiísticas. Pois, Chartier (1990) evidencia que a história cultural "tem por principal objecto identificar o modo como em diferentes lugares e momentos uma determinada realidade social é construída, pensada, dada a ler".

As percepções do social, esclarece Chartier (op.cit.), "não são de forma alguma discursos neutros", em virtude de produzirem "estratégias e práticas (sociais, escolares, políticas) que tendem a impor uma autoridade à custa de outros, por elas menosprezados". E, assim, contribui para "legitimar um projecto reformador ou a justificar, para os próprios indivíduos, as suas escolhas e condutas". Da mesma forma, o autor enfatiza a importância das lutas de representações comparando-as coma "as lutas econômicas para compreender os mecanismos pelos quais um grupo impõe, ou tenta impor, a sua concepção do mundo social, os valores que são os seus, e o seu domínio".

Deste modo, a definição de história cultural expressa por Chartier (op.cit.) pode contribuir na pesquisa acerca do processo de implementação do ensino da Língua Portuguesa no Maranhão do século XIX, e também como do processo da implantação de uma política lingüística.. Visto que, por um lado, "é preciso pensá-la como a análise do trabalho de representação" e, por outro lado, "esta história deve ser entendida como o estudo dos processos com os quais se constrói um sentido".

Portanto, corroboramos com a caracterização da História Intelectual, enfatizada por Lacerda (apud LOPES, op.cit.:30), uma vez que "continua a conceder atenção particular às produções culturais - obras filosóficas, historiográficas, poéticas, cientificas - distinguidas pela complexidade de estrutura". Para tanto, "a delimitação de seus contextos varia em função das questões formuladas pelo intérprete".

\section{2. $O$ contexto, 0 texto e a aproximação}

Para uma análise do ensino da Língua Portuguesa, a partir da segunda metade do século XIX, considerando a natureza essencialmente social da língua materna e de sua aprendizagem, são particularmente relevantes uma série de fatores históricos, econômicos, políticos e culturais que influenciaram a educação e o ensino de Língua 
Portuguesa no Brasil e, particularmente, no Maranhão. Assim sendo, de acordo com Soares apud Bastos (1998:54-55), a que a história da escola no Brasil revela que, também nesse período, "o ensino destinava-se, fundamentalmente, às camadas privilegiadas da população, as únicas que tinham acesso assegurado à escolarização". Em vista disso, tais detinham um razoável domínio da chamada 'norma padrão culta' ao chegarem às aulas de Português, exigido pela escola.

Com efeito, verificou-se ser a função do ensino da Língua Portuguesa, fundamentalmente, levar ao conhecimento, ou ao reconhecimento, das normas e regras de funcionamento desse dialeto de prestígio. Desta maneira, o ensino da gramática, enfatizado como respeito da língua, além do contato com textos literários, era utilizado para o desenvolvimento das habilidades de ler e escrever, assim o ensino do português restringia-se à alfabetização. Após este acesso a uma escolarização mais prolongada, os alunos passavam diretamente à aprendizagem da gramática da Língua Latina, da retórica e da poética.Acrescente-se, ainda, que a denominação de disciplina escolar "Português" ou "Língua Portuguesa" só passou a existir nas últimas décadas do século XIX, em virtude da língua ter sido estudada na escola sob a forma das disciplinas Gramática, Retórica e Poética. Mesmo assim, a disciplina "Português" continuou sendo, basicamente, o estudo da gramática da língua e leitura, para compreensão e imitação de autores portugueses e brasileiros.

Com relação à literatura de língua portuguesa, Martins (1988:8) enfatiza que houve um considerável enriquecimento, destacando-se a prosa de ficção (romance, novela, conto), além do jornalismo e o teatro, como surto cultural da época. Essa renovação expressava o movimento histórico-cultural, uma vez que particularizamos o setor da língua portuguesa, e revelava a atuação de escritores como Gonçalves Dias, José de Alencar, Aluísio de Azevedo, Machado de Assis, Cruz e Sousa, Euclides da Cunha.

Por outro lado, a história da língua, no século XIX, não tem sido bastante estudada, tendo em vista que o "ensino era essencialmente humanístico, em que a gramática, a retórica, a literatura e as línguas tinham particular relevo; o português escolar estava divorciado da língua falada pelo povo, cuja maioria era analfabeta", esclarece Martins (op.cit.:9-10).

Ao considerarmos, portanto, a legislação escolar como sendo um precioso documento para estudo da evolução de uma sociedade e do caráter de uma civilização, convém lembrar que nos deparamos, nesse final de século, exatamente com a continuidade de estrutura social e econômica e do desenvolvimento do "tipo de cultura" colonial, produto de uma civilização fundada na escravidão.

Na metade do século XIX, a educação é apontada como uma época de férteis realizações, porém, restritas em sua maioria ao município da Corte, em virtude da lei em vigor. Dentre tais realizações, elencamos a criação da Inspetoria Geral da Instrução Primária e Secundária do Município da Corte e estabelecimento das normas para o exercício da liberdade de ensino e de um sistema de preparação do professor primário.

Quanto aos estabelecimentos públicos de instrução secundária, dependendo das províncias, eram designados por nomes diferentes; assim, nas Províncias do Amazonas, Piauí, Alagoas, Bahia, Maranhão e Espírito Santo, são os Liceus Provinciais; no Pará, Colégio Paraense; no Rio Grande do Norte, Ateneu etc. No Liceu Maranhense, as matérias constituíam-se de Latim, Francês, Inglês, Gramática Geral, Geografia, Retórica, Filosofia, História Universal, Matemática e Cálculo e Escrituração Mercantil, de cunho literário. (Cf. Moacyr, 1939)

No Maranhão, a partir do final da década de 60 até o advento da República, houve um menor interesse, até mesmo um descaso, da Administração local pelo 
desenvolvimento da instrução pública, explicadas a partir das próprias mudanças que se efetivaram na estrutura política e econômica maranhense.

Por outro lado, numa perspectiva dominante, observa-se que as preocupações com a instrução primária são concretizadas em projetos, afirma Cabral (op cit.:33). Tais projetos, além de criticar a reforma anterior do ensino, defendiam uma nova organização escolar, baseada na idéia de liberdade de ensino. Em vista disso, surgiram depoimentos de alguns presidentes da Província maranhense corroborando com a idéia de que a educação favorecia o progresso das nações, tais como o do presidente Souza Aguiar, no qual enfatizava que "da organização da instrução pública depende o futuro das nações", além do presidente Maia que afirmava ser a educação o 'remédio' que impulsionava o homem ao trabalho e, portanto, este era a grande causa da riqueza das nações, estando, pois, depositada na educação 'a grande esperança da Província'.

Pela primeira vez, no Maranhão, se fez do estudo da língua materna, não um mero degrau para as outras disciplinas, mas um estudo aturado e profundo dessa primeira base de uma boa educação literária, no colégio Instituto de Humanidades, em 1864, fundado por Francisco Sotero dos Reis.

O desenvolvimento da instrução pública tratava-se, em grande parte, de uma questão financeira, visto que as províncias faziam o que podiam, contudo recorreram à filantropia dos ricos com o estabelecimento de associações beneficentes, em cujos fins entra a instrução pública. Outra atitude realizada fora da Corte, foi a idéia das escolas noturnas, "pela primeira vez na província em 1868, não tardou a ser abraçada pelas outras", enfatiza Oliveira (1874:52-53), assim o Império possui 136 escolas dessa natureza, sendo 83 públicas e 53 particulares, totalizando 5720 alunos. Inclusive, evidencia-se a criação de bibliotecas e gabinetes de leitura que comprova a tendência da época para o desenvolvimento da instrução.

A legislação reguladora do ensino superior, por sua vez, é enfatizada pelo decreto 7247, de 19 de abril de 1879, no qual Leôncio de Carvalho instituiu a liberdade de ensino e de frequiência e também modificou o plano das faculdades oficiais. Tais reformas representavam um esforço no sentido de adaptá-las a novas necessidades da técnica das profissões e marcaram progressos sensíveis na evolução do ensino superior do Império, ressalta Azevedo (1971:587).

Na segunda metade do século XIX, aumenta o número de gramáticas da língua portuguesa comprometidas em manter a tradição clássica latina, por isso não refletiam a língua escrita e falada no período, em virtude de serem considerados os modelos clássicos o ideal absoluto, enfatiza Martins (op.cit.:10). Uma análise dos manuais didáticos utilizados para o ensino da língua nas primeiras décadas do século XX, até os anos 60, comprova essa afirmação. Desta maneira, esses manuais eram uma gramática e uma antologia: lembre-se de algumas gramáticas utilizadas na Província do Maranhão: em 1859, o Compendio de grammatica philosophica da lingua portugueza, $4^{\circ}$ edição, autoria do padre Antônio da Costa Duarte, foi escolhido para o uso do Liceu do Maranhão. Em 1862, é editada a obra Postillas de grammatica geral, applicada á lingua portugueza pela analyse dos clássicos e em 1866 a Grammatica Portugueza. Accomodada aos principios geraes da palavra seguidos de immediata applicação pratica, ambas de autoria de Francisco Sotero dos Reis.

A gramática analisada nesse trabalho é a Grammatica Portugueza. Accomodada aos principios geraes da palavra seguidos de immediata applicação pratica, de 1871, segunda edição, de Francisco Sotero dos Reis, considerado um dos célebres gramáticos maranhenses que, na redação de periódicos e gramáticas, solidificou o conceito de filólogo profundo, gramático abalisado, exímio conhecedor da língua, familiar dos clássicos, reputação avultava no magistério. 
Exerceu diversos cargos públicos de eleição popular, a saber o de vereador, membro dos conselhos gerais da província, inclusive deputado da Assembléia provincial legislativa. Foi condecorado com o grau de cavaleiro das Ordens de Cristo e imperial da Rosa, em 1863, em atenção a seus estudos e trabalhos literários. Exerceu o cargo de professor da língua latina no Liceu e, também de literatura do Instituto de Humanidades. É sócio fundador e presidente da Associação Instituto Literário Maranhense, que tem por fins principais o estudo da historia pátria, e a propagação da instrução e conhecimentos úteis. Exerceu também as tarefas de jornalista, em periódicos, a exemplo de o Maranhense, o Constitucional, assim como redigiu o Publicador maranhense, diário oficial, esclarece Leal (1874).

Assim sendo, os filhos de Francisco Sotero Reis, que editam essa obra, revelam na introdução que "desde o seu aparecimento foi logo saudada por todos como perfeição do estilo, na perspiciudade e precisão das definições e regras doutrinais, por isso, achase ela com justiça adotada nas aulas públicas das principais províncias do Império". Nos Prolegômenos, repetidos da primeira edição, o autor apresenta a divisão da Gramática em Etimologia, Sintaxe, Ortografia e Prosódia. Uma vez que a Gramática divide-se em Gramática Geral e Gramática Particular, sendo "A Grammatica Geral é a sciencia dos principios immutaveis e geraes da palavra pronunciada ou escripta em todas as linguas", enquanto que "A Grammatica Particular é a arte de apllicar aos principios immutaveis e geraes da palavra as instituições arbitrarias e usuaes de qualquer língua" Portanto, a "Grammatica Portugueza, pois, é a arte de applicar aos principios immutaveis e geraes da palavra os usos e idiotismos da lingua portugueza".

Em vista disso, a adequação será realizada com a Gramática da Língua Portuguesa, do autor Celso Ferreira da Cunha, numa tentativa de aproximação moderna do vocabulário técnico.

\section{Perspectivas finais}

Em vista do que foi exposto, uma abordagem historiográfica da Língua Portuguesa tem relevância primordial nesse estudo, uma vez que a pesquisa ocorrerá no Maranhão, abrangendo o contexto histórico e documental do século XIX.

Esse trabalho, portanto, poderá contribuir para o desvelamento de questões concernentes à política lingüística, além de suscitar outras reflexões acerca do ensino de Língua Portuguesa no Maranhão.

\section{Referências Bibliográficas}

ALTMAN, C. A pesquisa lingüística no Brasil (1968-1988). São Paulo: Humanitas, 1998.

AZEVEDO, F. A cultura brasileira. 5.ed., revista e ampliada. São Paulo: Melhoramentos, editora da USP, v.13, 1971.

BASTOS, N.M.O.B. et al. Língua Portuguesa a través dos séculos (XVI ao XX): em busca do método historiográfico. Araraquara: Anais II EDIP, 2002.

BURKE, P. A escola dos Annales (1929-1989). São Paulo: UNESP, 1997.

CABRAL, M. S. C. Política e educação no Maranhão: 1834-1889. S.Luís: SIOGE, 1984.

CARDOSO, C. F.\& VAINFAS, R. Domínios da história. Rio de Janeiro: Campus, 1997.

CHARTIER, R. História cultural. Rio de Janeiro: Bertrand Brasil, 1990. 
DE CLERQ, J.; SWIGGERS, P. L'Histoire de la Linguistique: L'autre Histoire et L' Histoire d'une Histoire. Neue Fragüen der Linguistik org. por Elizabeth Felbusch, Reiner Pogarell e Cornelia Weiss. Tübingen: Verlag, 1991.

KOERNER, E. F. K. "Questões que persistem em Historiografia Lingüística.”[Trad. De Cristina Altman do orig. inglês "Persistent Issues in Linguistic Historiography." Professing Linguistic Historiography. Amsterdan \&^Philadelphia: John Benjamins. 1995] ANPOOL. Revista da Associação Nacional de Pós-graduação em Letras e Lingüística 2. 1996. p. 45-70

KUNH, T.A. A estrutura das revoluções científicas. 5.ed. São Paulo: Perspectiva, 2000. LEAL, A.H. Pantheon maranhense. Ensaios biographicos dos maranhenses illustres ja falecidos. 1874.

LOPES, M. A. (Org.). Grandes nomes da História Intelectual. São Paulo: Contexto, 2002.

MARTINS, N.S. História da língua portuguesa: século XIX. São Paulo: Ática, 1988.

MOACYR, P. A instrução e as províncias: subsídios para a história da educação no Brasil: 1834-1889. Cia Ed. Nacional, 1939.

OLIVEIRA, A. de Almeida. O ensino público. Obra destinada a mostrar o Estado, em que se acha, e as reformas, que exige a instrucção publica no Brazil. Maranhão, 1874.

SOARES, M. Concepções de linguagem e o ensino da língua portuguesa. In: BASTOS, N.B. (org.) Língua portuguesa: história, perspectivas, ensino. São Paulo: EDUC, 1998. (eventos).

Abstract: This work focalizes the process of the implementation of Portuguese language teaching in Maranhão, from $18^{\text {th }}$ to $20^{\text {th }}$ century, and aims, mainly, at describing how the linguistic knowledge was acquired and developed in this period. In order to do that, the study fixes its theoretical basis on Linguistic Historiography to show the cultural implications about several moments of this process. So, the methodological procedures will favour the three principles designed by Koerner (1996) to unveil the teaching view present in each century and the historiographic journey in Maranhão by means of primaries and secondaries sources.

Keywords: Portuguese language, Linguistic Historiography, Maranhense question 
